\title{
ANALISIS PENGENDALIAN KUALITAS MENGGUNAKAN METODE $S I X$ SIGMA DALAM MENINGKATKAN KINERJA OPERASIONAL DIVISI FIXED PLANT MAINTENANCE DI INDUSTRI PERTAMBANGAN PT BERAU COAL
}

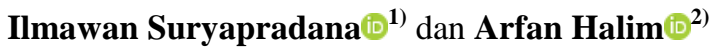 \\ ${ }^{1,2}$ Perawatan Mesin, Politeknik Sinar Mas Berau Coal \\ 1,2 J1 Raja Alam 2 Kelurahan Sei Bedungun, Kecamatan Tanjung Redeb, Kabupaten Berau 77315 \\ E-mail : ilmawan@polteksimasberau.ac.id ${ }^{1)}$, arfan.halim@polteksimasberau.ac.id ${ }^{2)}$
}

\begin{abstract}
ABSTRAK
Penelitian ini bertujuan untuk mengetahui peningkatan efektivitas mesin coal crusher dengan menggunakan analisis deskriptif dan kuantitatif metode six sigma. Penggunaan Overall Equipment Effectiveness dan Six Big Losses untuk menentukan nilai Overall Equipment Effectiveness dan faktor dominan yang menyebabkan rendahnya kinerja mesin atau peralatan. Proses penerapan small group activity sebagai bagian dari Total Productive Maintenance dengan penerapan fase DMAIC dari analisis Overall Equipment Effectiveness (OEE), Six Big Losses, dan Fish Bone Diagram untuk menganalisa penyebab masalah yang menghambat kinerja mesin dan peralatan serta signifikansi peningkatan kinerja operasional di departemen FPM. Berdasarkan pengolahan data pada Coal Crusher dengan metode OEE dan Six Big Losses faktor yang paling dominan menyebabkan rendahnya kinerja mesin adalah Reduced Speed Losses dengan persentase 58,82\% dan Equipment Failure Losses dengan persentase 62,21\% pada mesin Coal Crusher yang mempengaruhi efektivitas dan produktivitas mesin tersebut. Menggunakan diagram pareto untuk menganalisis data losses yang ada sehingga akar permasalahan dapat ditemukan. Selanjutnya dengan analisis fish bone diagram didapatkan saran-saran langkah pencegahan dalam mengurangi jumlah losses time. Langkah perbaikan sistem yang dilakukan di Departemen FPM dengan penerapan Small Group Activity sebagai control secara berkelanjutan memberi peningkatan produktivitas terhadap kinerja Coal Crusher di akhir periode Desember 2020 yaitu diperoleh rata-rata nilai Overall Equipment Effectiveness (OEE) yaitu sebesar $87 \%$ dan telah memenuhi nilai standar dunia $85 \%$. Dengan adanya peningkatan kinerja diharapkan kegiatan proses produksi dapat berjalan efektif, efisien, serta energi dapat digunakan secara optimal.
\end{abstract}

Kata Kunci: Six Sigma, DMAIC, OEE, Small Group, Coal Crusher

\section{PENDAHULUAN}

Dalam beberapa dekade terakhir, perawatan mesin dan peralatan produksi telah berkembang menjadi salah satu bidang terpenting dalam lingkungan bisnis karena peningkatan persaingan global menyebabkan perubahan luar biasa dalam cara perusahaan beroperasi untuk bisa bersaing sehingga melakukan berbagai usaha untuk meningkatkan mutu, efisiensi dan produktivitas (Saleem et al., 2017). Menurut (Modgil and Sharma, 2016) perubahan dalam cara pandang perusahaan ini telah mempengaruhi cara perawatan mesin dan peralatan produksi dalam mendukung keberhasilan bisnis dalam persaingan global dengan produktivitas dan mutu yang meningkat serta biaya menurun. (Rastegari and Salonen, 2015) selanjutnya menambahkan bahwa penerapan konsep lean adalah salah satu perubahan signifikan dalam setiap perusahaan, dimana dengan memperkenalkan konsep lean dalam setiap industri yang dimulai dari industri manufaktur berupa Just In Time dan Demand Flow Technology untuk sukses di pasar yang penuh persaingan.

Akibatnya, permintaan untuk peralatan produksi yang dapat diandalkan meningkat. Kebutuhan untuk memiliki ketersediaan peralatan produksi yang tinggi menyebabkan perusahaan memerlukan strategi pemeliharaan yang lebih efektif dan efisien untuk mencapai sistem produksi yang kompetitif dengan mengoptimalkan pemeliharaan peralatan produksi sebagai salah satu aspek kunci dari perbaikan berkelanjutan perusahaan karena mesin merupakan bagian dari aset perusahaan yang sangat penting (Salonen, 2011). Untuk mencapai kinerja kelas dunia, Hooi \& Leong menyatakan bahwa semakin banyak perusahaan yang mengganti strategi reaktif dan perbaikan setelah ada kerusakan (Corrective Maintenance) dengan strategi proaktif seperti pemeliharaan pencegahan (Preventive Maintenance) dan perawatan prediksi (Predictive Maintenance) maupun strategi agresif seperti pemeliharaan produktif total (Total Productive Maintenance) (Hooi and Leong, 2017). TPM menekankan pada tiga konsep, yaitu efektivitas peralatan yang optimal, kegiatan kelompok kecil (small group activity) dan pemeliharaan operator. Modgil \& Sharma dalam penelitiannya menyatakan bahwa TPM terkait erat dengan TQM (Total Quality Management) karena keduanya diarahkan untuk membuat perusahaan lebih kompetitif dengan TPM lebih ke arah operasi lapangan dan TQM lebih tentang elemen 
strategis seperti inovasi produk, mutu dan pelaporan data, penelitian dan pengembangan (R\&D) dan pemanfaatan teknologi, dimana salah satu metode yang sering digunakan dalam TQM adalah metode six sigma yang menggunakan fase DMAIC (define, measure, analyse, improve, control) (Modgil and Sharma, 2016). Menurut Brodny \& Tutak, strategi TPM bisa juga diterapkan di industri pertambangan meskipun masih jarang penelitian yang membahasnya sampai tuntas terkhusus pertambangan batubara (Brodny and Tutak, 2017). Di samping itu, Pourjavad \& Shirouyehzad dalam penelitiannya menjelaskan bahwa TPM adalah satu manajemen strategic perawatan yang paling berpengaruh di industri pertambangan (Pourjavad et al., 2013).

Batubara merupakan mineral organik yang dapat terbakar, terbentuk dari sisa tumbuhan purba yang mengendap dan selanjutnya berubah bentuk akibat proses fisika dan kimia yang berlangsung selama jutaan tahun. Oleh karena itu, batubara adalah bahan bakar fosil. Proses perubahan tumbuhan menjadi batubara disebut dengan pembatubaraan (coalification). PT Berau Coal sebagai salah satu Perusahaan Tambang Batubara menyadari pentingnya kualitas dalam setiap proses penambangan batubara. Dengan proses kerja penambangan batubara Open Pit Mining yaitu cara penambangan secara terbuka dalam pengertian umum.

Coal handling system merupakan sistem untuk menangani mulai dari pembongkaran batubara dari kapal/tongkang (Unloading Area) sampai ke area penimbunan/penyimpanan di stock pile ataupun langsung pengisian ke bunker, yang selanjutnya digunakan untuk pembakaran di boiler (Wicakmoko, 2016). Secara umum komponen utama coal handling system ialah unloading area, belt conveyor, diverter gate, hopper, chute, coal crusher, transfer tower, stacker reclaimed, dan coal bunker. Dalam coal handling system, coal crusher merupakan peralatan utama yang berfungsi menghancurkan batubara yang melewati peralatan tersebut yang mempunyai ukuran lebih besar (>32 mm), sehingga menjadi batubara dengan ukuran kecil. Dengan adanya coal crusher, batubara yang ditransfer menuju bunker ukurannya sudah kecil $(<32 \mathrm{~mm})$ sehingga dapat menghindari tersumbatnya screen inlet bunker dan meringankan kerja mill. Namun dalam proses produksinya mesin coal crusher sering digunakan diluar batas normal karena untuk memenuhi target produksi dan jauh dari kata andal karena keandalan merupakan kemampuan dari sistem atau komponen untuk menjalankan fungsinya yang diperlukan di bawah kondisi yang menjadi syarat jangka waktu tertentu tanpa adanya kegagalan (Prasetyoaji et al., 2019).

Total Productive Maintenance (TPM) merupakan filosofi dari Jepang yang dikembangkan berdasarkan konsep dan metodologi perawatan yang produktif. Konsep ini pertama kali diperkenalkan oleh M/s Nippon Denso Co. Ltd. dari Jepang yang merupakan pemasok M/s Toyota Motor Company pada tahun 1971. TPM adalah pendekatan inovatif dalam perawatan alat yang mengoptimalkan efektivitas peralatan, menghilangkan kerusakan dan mengandalkan perawatan otonom oleh operator melalui kegiatan sehari-hari dengan mengimplementasikan berbagai proyek kaizen (Dogra et al., 2011). Menurut penelitian Ahuja \& Khamba, TPM menjadikan perawatan yang fokus sebagai bagian penting dari bisnis. Penerapan TPM bertujuan untuk meningkatkan daya saing organisasi dengan pendekatan terstruktur yang kuat untuk mengubah pola pikir karyawan sehingga membuat perubahan nyata dalam budaya kerja organisasi. TPM akan melibatkan semua tingkatan dan fungsi dalam suatu organisasi untuk memaksimalkan efektivitas keseluruhan mesin dan peralatan produksi (Singh and Ahuja, 2014). Metode ini selanjutnya menyempurnakan proses dan peralatan yang ada dengan mengurangi kesalahan dan kecelakaan. Shirose dalam bukunya juga menjelaskan bahwa penerapan TPM merupakan kebutuhan perusahaan kelas dunia yang berupaya mengoptimalkan efektivitas peralatan produksi dengan departemen perawatan adalah pusat utama program perawatan pencegahan dengan berupaya melibatkan karyawan dari semua departemen dan tingkatan yang terendah hingga eksekutif senior untuk memastikan operasi peralatan yang efektif (Shirose, 2017). Menurut Suzuki, TPM melibatkan semua pekerja melalui kegiatan kelompok kecil (small group activity, SGA) (Suzuki, 2017). Di samping itu, Hooi \& Leong menjelaskan bahwa TPM merupakan sistem perawatan komprehensif yang mencakup perawatan pencegahan untuk mencegah kerugian dan pemborosan (Gupta and Vardhan, 2016).

Divisi Fixed Plant Maintenance merupakan salah satu divisi yang memberikan support kegiatan produksi dengan output berupa ketersediaan alat yang memiliki performance sesuai standar dengan biaya yang reasonable. Kegiatan pemeliharaan alat atau Maintenance adalah kegiatan untuk meyakinkan fisik aset senantiasa berfungsi dan kinerjanya sesuai standar yang diinginkan. Maintenance merupakan perawatan untuk mencegah hal-hal yang tidak diinginkan seperti kerusakan terlalu cepat terhadap semua peralatan baik yang sedang bekerja atau yang berfungsi sebagai suku cadang.

Berdasarkan latar belakang di atas, penelitian ini berfokus pada penerapan small group activity sebagai bagian dari TPM dengan menggunakan six sigma di industri pertambangan batubara pada divisi Fixed Plant Maintenance PT Berau Coal.

\section{RUANG LINGKUP}

Ruang lingkup dalam penelitian ini adalah sebagai berikut :

1. Cakupan permasalahan pada penelitian ini adalah analisis performance pada Coal Crusher-03 dan Coal Crusher-04.

2. Batasan dalam penelitian ini hanya dilakukan analisis OEE, Six Big Losses dan Penerapan Six Sigma. 
3. Dengan Penerapan Small Group Activity pada Departemen Fixed Plant Maintenance dapat meningkatkan dan mempertahankan performance dan produktivitas Coal Crusher.

\section{BAHAN DAN METODE}

Metode penelitian yang digunakan menggunakan analisis kuantitatif. Penelitian kuantitatif menggunakan angka sebagai data pokoknya, sehingga analisisnya menggunakan prinsip-prinsip statistik. Ada bentuk umum yang dapat membedakan jenis data statistik, yakni deskriptif dan korelatif. Statistik dapat dianggap deskriptif, jika menggambarkan karakter sampel dan dianggap korelatif jika menggambarkan kekuatan dan arah hubungan (Sugiyono, 2013).

Penelitian ini dilakukan di Fixed Plant Maintenance (FPM) adalah sebuah departemen yang mempunyai tugas untuk melakukan maintenance atau perawatan terhadap unit Crusher dan Genset yang diperlukan untuk mempertahankan (retaining) dan mengembalikan (restoring) mesin ataupun peralatan kerja ke kondisi yang terbaik sehingga dapat melakukan produksi dengan optimal. Penelitian ini adalah penelitian terapan dengan menggunakan data primer dan data sekunder untuk mengetahui permasalahan dari rumusan masalah yang akan diteliti. Dengan menggunakan studi kasus tentang kinerja mesin Coal Crusher di site Binungan PT Berau Coal yang paling rendah diantara mesin-mesin yang sejenis di semua site tambang yang ada, maka dilakukan pengumpulan data primer yang diperoleh dengan wawancara maupun diskusi dalam small group activity, pengamatan proses produksi serta pemantauan mesin atau peralatan. Di samping itu, data sekunder diperoleh melalui data historis selama satu tahun dari Januari sampai dengan Desember 2020 seperti downtime, jumlah produksi, jumlah cacat, waktu non-produktif, jumlah kerusakan mesin, waktu perbaikan standar, produk harga, biaya komponen, dan biaya tenaga kerja.

\subsection{Siklus DMAIC}

Six Sigma $(\sigma)$ adalah simbol yang digunakan untuk menunjukkan penyimpangan standar (standar deviasi), suatu indikator dari tingkat variasi dalam seperangkat pengukuran atau proses (Evans and Lindsay, 2014). Tingkat kualitas Sigma biasanya juga dipergunakan untuk menggambarkan output dari suatu proses. Semakin tinggi tingkat sigma maka semakin kecil toleransi yang diberikan pada kecacatan dan semakin rendah variabilitas output yang dihasilkan. Six Sigma merupakan sebuah konsep statistik yang dapat menjawab kebutuhan consumer akan suatu kualitas yang tinggi dan proses bisnis yang bebas defect dengan tidak lebih dari 3,4 kegagalan (error) dari satu juta kesempatan. Six Sigma adalah culture yang berfokus untuk meningkatkan consumer satisfaction, menurunkan biaya, dan memperbaiki profitabilitas dengan cara menekankan pada pemahaman, pengukuran dan perbaikan proses secara terus menerus (Gaspersz, 2011).
Six Sigma menggunakan alat statistik untuk mengidentifikasi faktor vital, siklus DMAIC adalah proses kunci untuk meningkatkan secara kontinyu target Six Sigma. DMAIC dilaksanakan secara sistematik berdasarkan data dan fakta, berikut ini adalah tahapan dalam siklus DMAIC dan langkah-langkah pelaksanaan setiap tahap (Sin et al., 2015) :

\subsection{Define (D)}

Tahap Define merupakan langkah operasional pertama dalam program peningkatan kualitas Six Sigma. Dalam tahap ini dilakukan penentuan sasaran dan identifikasi Coal Crusher berdasarkan data produksi.

\subsection{Measure (M)}

Beberapa hal yang dilakukan dalam tahap ini yaitu pengukuran efektivitas dengan metode Overall Equipment Effectiveness (OEE) diambil dari laporan kerusakan serta jumlah produksi mesin coal crusher dari bulan Januari sampai Desember 2020 (Rimawan and Raif, 2016).

\subsection{Analyse (A)}

Tahap ini merupakan tahap menganalisa, mencari dan menemukan penyebab dari suatu masalah. Hal ini dapat menggunakan analisis Six Big Losses, untuk menunjukkan faktor-faktor penyebab dan karakteristik kualitas.

\subsection{Improve (I)}

Setelah sumber dan akar penyebab permasalahan teridentifikasi, maka perlu dilakukan penetapan rencana tindakan untuk peningkatan kualitas Six Sigma, yaitu dengan menggunakan diagram pareto dan diagram sebab akibat pada mesin Coal Crusher. Pada tahap ini, Six Big Losses digunakan untuk menentukan prioritas rencana perbaikan.

\subsection{Control $(\mathrm{C})$}

Tahap ini merupakan tahap untuk mengendalikan proses yang sudah diperbaiki. Pengendalian tersebut dilakukan dengan pelaksanaan Small Group Activity di Departemen Fixed Plant Maintenance.

Pendekatan DMAIC dengan menggunakan alat (tools) yang telah disebutkan sebelumnya dilakukan untuk mendapatkan usulan peningkatan pada mesin Coal Crusher, dapat dilihat pada gambar 1 diagram alir penelitian. 


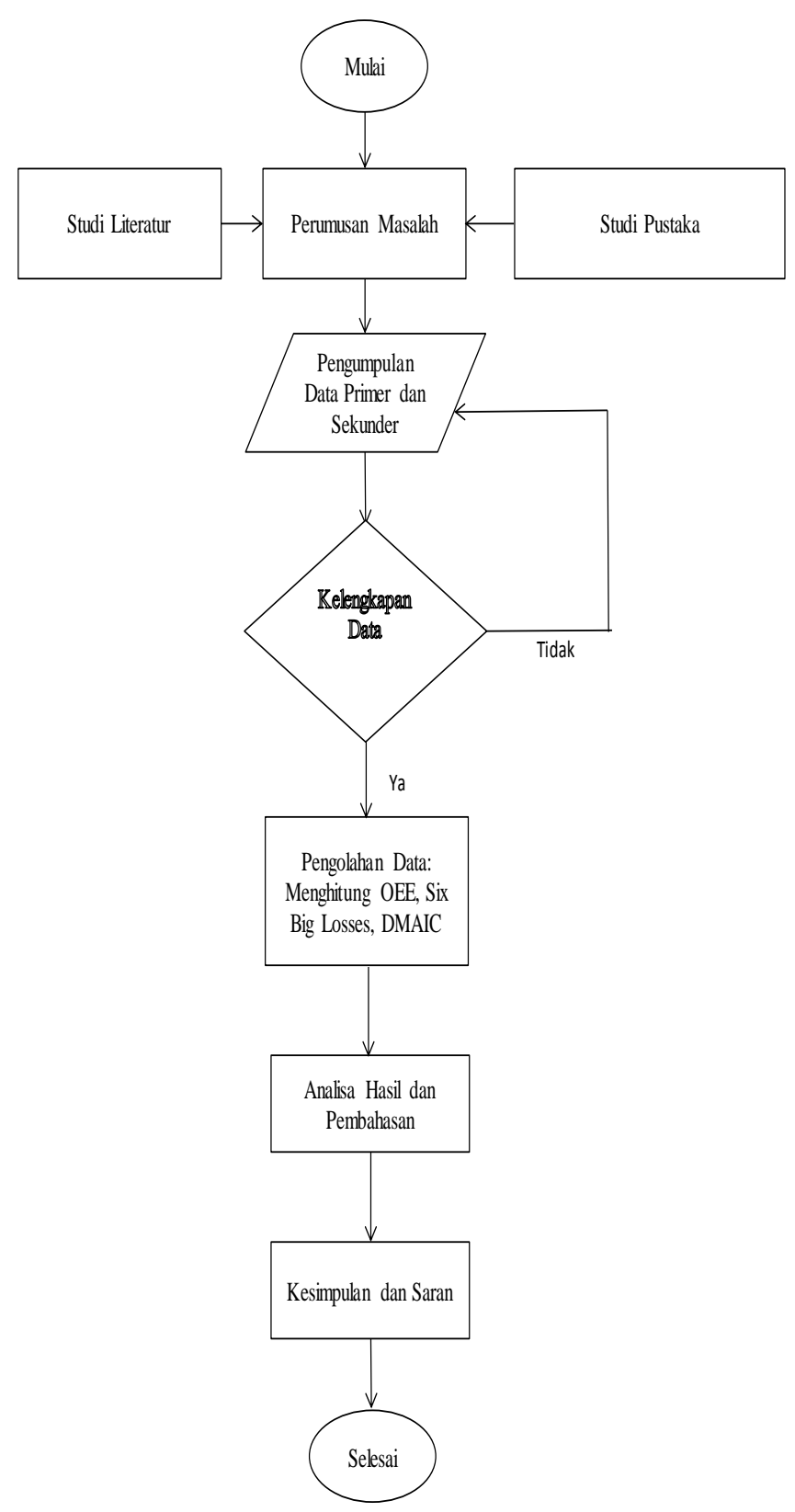

Gambar 1. Diagram Alir Penelitian

\section{PEMBAHASAN}

Upaya peningkatan menuju target Six Sigma dilakukan dengan metode define, measure, analyse, improve dan control langkah-langkah tahap pelaksanaannya sebagai berikut:

\subsection{Define}

Tahap awal dalam pendekatan DMAIC adalah identifikasi hal-hal terkait downtime, produksi Coal Crusher dapat dilihat pada tabel 1, tabel 2, dan tabel 3.
Tabel 1. Data Downtime Coal Crusher 03 dan 04

\begin{tabular}{|c|c|c|}
\hline MONTH & $\begin{array}{c}\text { CRUSHER 03 } \\
\text { (LINE-A) } \\
\text { Downtime ( Jam ) }\end{array}$ & $\begin{array}{c}\text { CRUSHER 04 } \\
\text { (LINE-B) } \\
\text { Downtime( Jam ) }\end{array}$ \\
\hline JANUARY & 7.02 & 1.7 \\
\hline FEBRUARY & 13.43 & 29.02 \\
\hline MARCH & 22.52 & 17.57 \\
\hline APRIL & 62.38 & 5.25 \\
\hline MAY & 223.75 & 4.08 \\
\hline JUNE & 5.83 & 14.42 \\
\hline JULY & 25.25 & 19.63 \\
\hline AUGUST & 35.5 & 7 \\
\hline SEPTEMBER & 15.32 & 6.82 \\
\hline OCTOBER & 38 & 8.17 \\
\hline NOVEMBER & 18.33 & 9.67 \\
\hline DECEMBER & 1.42 & 7.67 \\
\hline TOTAL & $\mathbf{4 6 8 . 7 5}$ & $\mathbf{1 3 1}$ \\
\hline
\end{tabular}

Sumber : Dept. FPM

Tabel 2. Data Produksi Batubara Crusher-03

\begin{tabular}{|c|c|c|c|}
\hline \multirow{2}{*}{ MONTH } & \multicolumn{3}{|c|}{ CRUSHER 03 (LINE-A) } \\
\cline { 2 - 4 } & TONAGE & $\begin{array}{c}\text { WH } \\
\text { UNIT }\end{array}$ & MT/HRS \\
\hline JANUARY & $205.358,493$ & 242,94 & 845,31 \\
\hline FEBRUARY & $194.167,54$ & 230,13 & 843,73 \\
\hline MARCH & $246.279,28$ & 321,40 & 766,27 \\
\hline APRIL & $263.055,67$ & 332,32 & 791,57 \\
\hline MAY & $130.489,98$ & 160,08 & 815,15 \\
\hline JUNE & $354.037,66$ & 427,20 & 828,74 \\
\hline JULY & $240.725,12$ & 310,01 & 776,51 \\
\hline AUGUST & $262.395,83$ & 306,90 & 854,99 \\
\hline SEPTEMBER & $239.606,32$ & 291,90 & 820,85 \\
\hline OCTOBER & $232.779,05$ & 285,86 & 814,31 \\
\hline NOVEMBER & $262.506,85$ & 340,98 & 769,86 \\
\hline DECEMBER & $278.994,96$ & 363,95 & 766,57 \\
\hline TOTAL & $\mathbf{2 . 9 1 0 . 3 9 6 , 7 6}$ & $\mathbf{3 . 6 1 3 , 6 7}$ & $\mathbf{8 0 5 , 3 9}$ \\
\hline
\end{tabular}

Tabel 3. Data Produksi Batubara Crusher-04

\begin{tabular}{|c|c|c|c|}
\hline \multirow{2}{*}{ MONTH } & \multicolumn{3}{|c|}{ CRUSHER 04 (LINE-B) } \\
\cline { 2 - 4 } & TONAGE & $\begin{array}{c}\text { WH } \\
\text { UNIT }\end{array}$ & MT/HRS \\
\hline JANUARY & $104,090,412$ & 143,67 & 724,51 \\
\hline FEBRUARY & $56.638,70$ & 75,49 & 750,28 \\
\hline MARCH & $99.298,14$ & 144,90 & 685,29 \\
\hline APRIL & $221.980,91$ & 321,65 & 690,13 \\
\hline
\end{tabular}




\begin{tabular}{|c|c|c|c|} 
MAY & $124.590,50$ & 164,44 & 757,67 \\
\hline JUNE & $84.350,90$ & 115,67 & 729,24 \\
\hline JULY & $76.841,41$ & 103,60 & 741,71 \\
\hline AUGUST & $116.552,71$ & 163,00 & 715,05 \\
\hline SEPTEMBER & $138.140,27$ & 205,08 & 673,59 \\
\hline OCTOBER & $117.344,39$ & 164,43 & 713,64 \\
\hline NOVEMBER & $101.974,64$ & 149,16 & 683,66 \\
\hline DECEMBER & $121.207,22$ & 182,05 & 665,79 \\
\hline TOTAL & $\mathbf{1 . 3 6 3 . 0 1 0 , 2 0}$ & $\mathbf{1 . 9 3 3 , 1 4}$ & $\mathbf{7 0 5 , 0 8}$ \\
\hline
\end{tabular}

Sumber : Dept. FPM

\subsection{Measure}

Data yang dibutuhkan dalam pengukuran efektivitas dengan metode overall equipment effectiveness (OEE) diambil dari laporan kerusakan serta jumlah produksi mesin coal crusher dari bulan Januari sampai Desember 2020.

Setelah semua informasi telah terkumpul melalui data historis perusahaan maka dilakukan pengolahan data. Dapat dilihat pada tabel 4 dan tabel 5, adalah tahap pertama pengukuran tiga ratio tersebut yaitu availability rate, performance rate, dan quality rate pada mesin coal crusher. Sebelum mendapatkan nilai OEE, dilakukan perhitungan ketiga komponen tersebut dari bulan Januari sampai Desember 2020 (Rimawan and Raif, 2016).

Tabel 4. Hasil Perhitungan OEE Coal Crusher-03

\begin{tabular}{|l|r|r|r|r|}
\hline Month & $\begin{array}{c}\text { Availability } \\
(\%)\end{array}$ & $\begin{array}{c}\text { Quality } \\
(\%)\end{array}$ & $\begin{array}{c}\text { Performance } \\
(\%)\end{array}$ & \multicolumn{1}{c|}{$\begin{array}{c}\text { OEE } \\
(\%)\end{array}$} \\
\hline JAN & 97 & 100 & 113 & 109 \\
\hline FEB & 94 & 100 & 112 & 106 \\
\hline MAR & 93 & 100 & 102 & 95 \\
\hline APR & 81 & 100 & 106 & 86 \\
\hline MAY & -40 & 100 & 109 & -43 \\
\hline JUNE & 99 & 100 & 110 & 109 \\
\hline JULY & 92 & 100 & 104 & 95 \\
\hline AUG & 88 & 100 & 114 & 101 \\
\hline SEPT & 95 & 100 & 109 & 104 \\
\hline OCT & 87 & 100 & 109 & 94 \\
\hline NOV & 95 & 100 & 103 & 97 \\
\hline DEC & 100 & 100 & 102 & 102 \\
\hline
\end{tabular}

Sumber : Pengolahan Data Sekunder

Tabel 5. Hasil Perhitungan OEE Coal Crusher-04

\begin{tabular}{|l|r|r|r|r|}
\hline Month & $\begin{array}{c}\text { Availability } \\
(\%)\end{array}$ & $\begin{array}{c}\text { Quality } \\
(\%)\end{array}$ & $\begin{array}{c}\text { Performance } \\
(\%)\end{array}$ & \multicolumn{1}{c|}{$\begin{array}{c}\text { OEE } \\
(\%)\end{array}$} \\
\hline JAN & 99 & 100 & 97 & 95 \\
\hline FEB & 62 & 100 & 100 & 62 \\
\hline
\end{tabular}

\begin{tabular}{|l|r|r|r|r|} 
MAR & 88 & 100 & 91 & 80 \\
\hline APR & 98 & 100 & 92 & 91 \\
\hline MAY & 98 & 100 & 101 & 99 \\
\hline JUNE & 88 & 100 & 97 & 85 \\
\hline JULY & 81 & 100 & 99 & 80 \\
\hline AUG & 96 & 100 & 95 & 91 \\
\hline SEPT & 97 & 100 & 90 & 87 \\
\hline OCT & 95 & 100 & 95 & 90 \\
\hline NOV & 94 & 100 & 91 & 85 \\
\hline DEC & 96 & 100 & 89 & 85 \\
\hline
\end{tabular}

Sumber : Pengolahan Data Sekunder

Dapat dilihat pada gambar 2, bagaimana perbandingan ketiga ratio OEE. Terlihat bahwa quality ratio memiliki nilai yang relatif tinggi karena tidak ada material batubara yang cacat (defect) pada proses penghancuran nya atau dengan kata lain reject $=0 \%$. Pada urutan kedua adalah performance ratio yang memiliki nilai rata-rata $108 \%$ dimana performance mesin coal crusher-03 dengan nilai tertinggi berada pada bulan Agustus dengan nilai $114 \%$. Sedangkan nilai terendah di bulan Maret sebesar $102 \%$ sehingga mengidentifikasikan bahwa nilai performance rate mesin coal crusher-03 telah melampaui dengan standar dunia yang diharapkan sebesar 95\%. Sedangkan di urutan ketiga ialah availability ratio yang memiliki nilai ratarata $82 \%$ dimana availability mesin coal crusher-03 dengan nilai tertinggi berada pada bulan Desember, Juni, dan Januari karena minimnya downtime sedangkan nilai terendah pada bulan Mei sebesar $-40 \%$ karena memiliki downtime tertinggi yakni sebesar 223.75 jam sehingga menurunkan nilai availability rate coal crusher, dimana nilai availability ratio masih jauh dari standar dunia yang diharapkan yaitu sebesar $90 \%$.

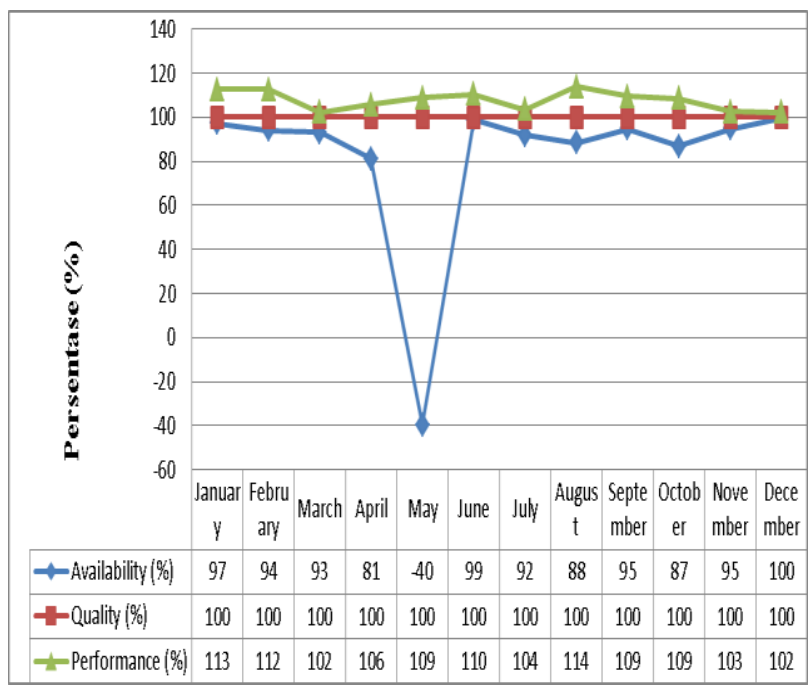

Gambar 2. Grafik perbandingan tiga ratio OEE Coal Crusher-03 Januari - Desember 2020 
Dapat dilihat pada gambar 3, bagaimana perbandingan ketiga ratio OEE. Terlihat bahwa quality ratio memiliki nilai yang relatif tinggi karena tidak ada material batubara yang cacat (defect) pada proses penghancuran nya atau dengan kata lain reject $=0 \%$. Pada urutan kedua adalah performance ratio yang memiliki nilai rata-rata $95 \%$ dimana performance mesin coal crusher-04 dengan nilai tertinggi berada pada bulan Mei dengan nilai $101 \%$. Sedangkan nilai terendah di bulan Desember sebesar $89 \%$ sehingga mengidentifikasikan bahwa nilai performance rate mesin coal crusher-04 telah sesuai dengan standar dunia yang diharapkan sebesar 95\%. Sedangkan di urutan ketiga ialah availability ratio yang memiliki nilai rata-rata $91 \%$ dimana availability mesin coal crusher-04 dengan nilai tertinggi berada pada bulan Januari, April, dan Mei karena minimnya downtime sedangkan nilai terendah pada bulan Februari sebesar 62\% karena memiliki downtime tertinggi yakni sebesar 29.02 jam sehingga nilai availability rate coal crusher-04 telah melampaui nilai availability ratio dari standar dunia yang diharapkan yaitu sebesar $90 \%$.

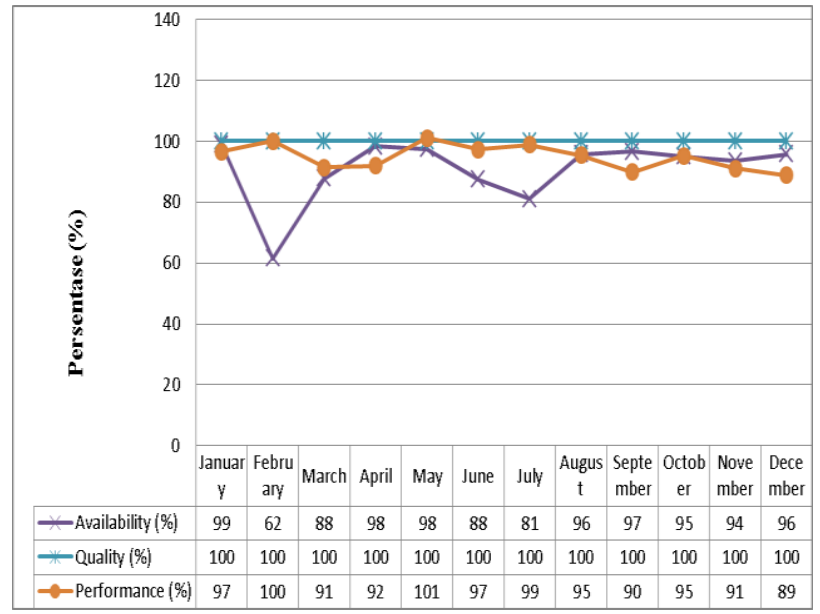

Gambar 3. Grafik perbandingan tiga ratio OEE Coal Crusher-04 Januari - Desember 2020

Dapat dilihat pada gambar 4, nilai rata-rata OEE pada mesin coal crusher-03 pada bulan Januari sampai Desember 2020 sebesar $88 \%$. Mesin coal crusher-03 memiliki nilai rata- rata availability sebesar $82 \%$ dan nilai ini berada dibawah dari standar dunia yaitu $90 \%$ yang menandakan tidak ada keseimbangan antara waktu operasi dan waktu beban dimana waktu operasi dipengaruhi oleh downtime mesin. Pada performance mesin coal crusher-03 memiliki nilai rata-rata $108 \%$ dan telah melampaui dengan nilai standar dunia yang telah ditetapkan yaitu $95 \%$ hal ini menunjukkan bahwa penggunaan mesin efisien karena sesuai dengan kapasitas mesin yang seharusnya. Sedangkan untuk faktor quality memiliki nilai $100 \%$ dikarenakan tidak ada material batubara yang defect.

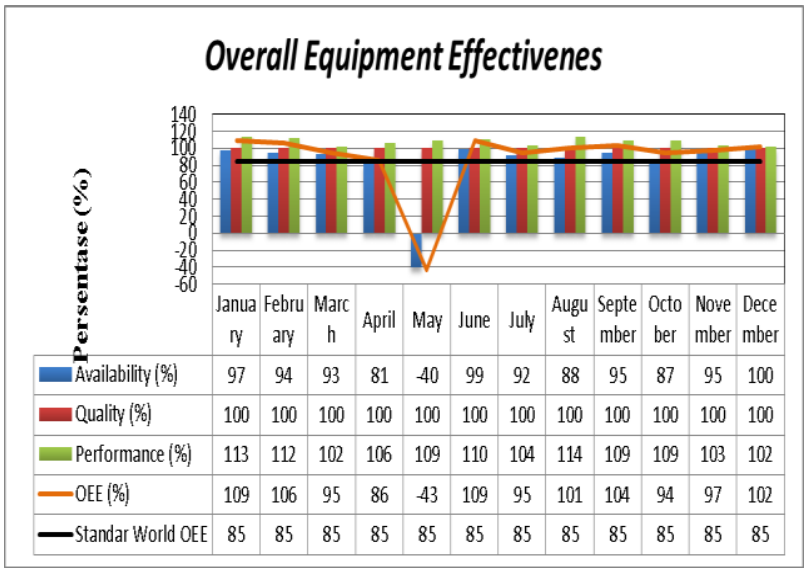

Gambar 4. Grafik Nilai OEE Mesin Coal Crusher-03 Januari - Desember 2020

Dapat dilihat pada gambar 5, nilai rata-rata OEE pada mesin coal crusher-04 pada bulan Januari sampai Desember 2020 sebesar $86 \%$. Mesin coal crusher-04 memiliki nilai rata- rata availability sebesar $91 \%$ dan nilai ini berada diatas dari standar dunia yaitu $90 \%$ yang menandakan adanya keseimbangan antara waktu operasi dan waktu beban. Pada performance mesin coal crusher04 memiliki nilai rata-rata $95 \%$ dan telah memenuhi dengan nilai standar dunia yang telah ditetapkan yaitu 95\% hal ini menunjukkan bahwa penggunaan mesin efisien karena sesuai dengan kapasitas mesin yang seharusnya. Sedangkan untuk faktor quality memiliki nilai $100 \%$ dikarenakan tidak ada material batubara yang defect.

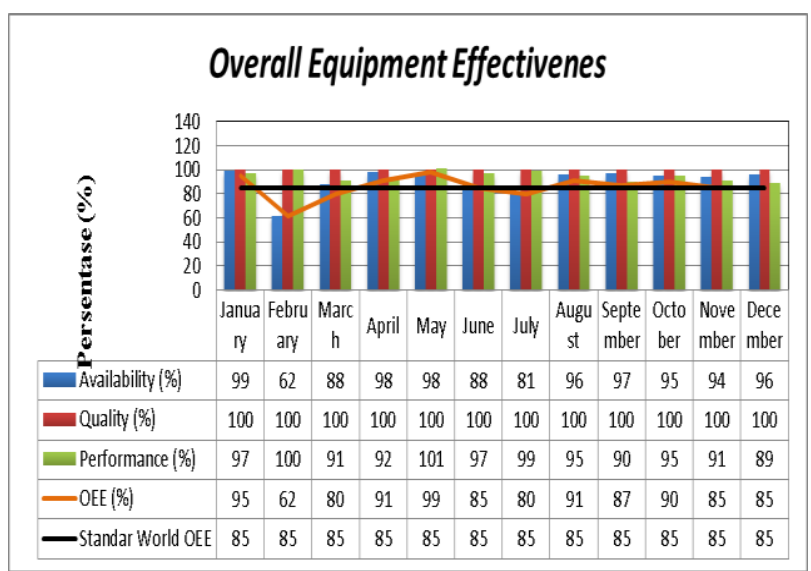

Gambar 5. Grafik Nilai OEE Mesin Coal Crusher-04 Januari - Desember 2020

\subsection{Analyse}

Penentuan jenis losses dominan dilakukan dengan menggunakan analisis Six Big Losses pada mesin Coal Crusher.

Dapat dilihat pada tabel 6 , persentase nilai equipment failure losses (EFL) yaitu sebesar 17,40\%, nilai Setup and Adjustment Losses (SAL) yaitu sebesar $0,65 \%$, nilai Reduced Speed Losses (RSL) yaitu sebesar 25,99\%, nilai Idle and Minor Stoppage Losses (IMSL) yaitu sebesar 
0,14\%. Pada bulan Mei 2020 terjadi downtime mencapai 223,75 jam, kerusakan terjadi yaitu chain putus dan penggantian plat hopper sehingga mempengaruhi nilai equipment failure losses (EFL) dan nilai Reduced Speed Losses (RSL).

Untuk tabel 7 persentase nilai equipment failure losses (EFL) yaitu sebesar 8,20\%, nilai Setup and Adjustment Losses (SAL) yaitu sebesar $0,76 \%$, nilai Reduced Speed Losses (RSL) yaitu sebesar 3,97\%, nilai Idle and Minor Stoppage Losses (IMSL) yaitu sebesar 0,25\%. Pada bulan Februari 2020 terjadi downtime mencapai 29,02 jam, kerusakan terjadi yaitu ganti belt dan pemasangan skirting sehingga mempengaruhi nilai equipment failure losses (EFL) dan nilai Reduced Speed Losses (RSL).

Sedangkan untuk nilai Rework Losses $0 \%$ dan Reduce Yield 0\% dikarenakan semua hasil crusher batubara sudah sesuai dengan pengaturan yang telah ditentukan.

Tabel 6. Hasil Perhitungan Six Big Losses Coal Crusher-03

\begin{tabular}{|l|r|r|r|r|r|l|}
\hline \multirow{2}{*}{ Month } & EFL & SAL & RSL & IMSL & RL & RY \\
\hline & \multicolumn{7}{|c|}{$\%$} \\
\hline January & 1.93 & 0.96 & 15.57 & 0.00 & 0.00 & 0.00 \\
\hline February & 4.79 & 1.05 & 18.31 & 0.00 & 0.00 & 0.00 \\
\hline March & 6.48 & 0.47 & 9.15 & 0.06 & 0.00 & 0.00 \\
\hline April & 18.19 & 0.58 & 24.29 & 0.00 & 0.00 & 0.00 \\
\hline May & 137.80 & 0.94 & 148.43 & 1.04 & 0.00 & 0.00 \\
\hline June & -0.33 & 0.33 & 11.84 & 0.00 & 0.00 & 0.00 \\
\hline July & 7.26 & 0.67 & 11.65 & 0.22 & 0.00 & 0.00 \\
\hline August & 11.24 & 0.33 & 25.54 & 0.00 & 0.00 & 0.00 \\
\hline September & 3.96 & 1.28 & 14.67 & 0.00 & 0.00 & 0.00 \\
\hline October & 12.65 & 0.29 & 21.84 & 0.35 & 0.00 & 0.00 \\
\hline November & 4.62 & 0.76 & 8.00 & 0.00 & 0.00 & 0.00 \\
\hline December & 0.21 & 0.18 & 2.57 & 0.00 & 0.00 & 0.00 \\
\hline
\end{tabular}

Sumber : Pengolahan Data Sekunder

Tabel 7. Hasil Perhitungan Six Big Losses Coal Crusher-04

\begin{tabular}{|l|r|r|r|r|r|r|}
\hline Month & EFL & SAL & RSL & IMSL & RL & RY \\
\hline & \multicolumn{7}{|c|}{$(\%)$} \\
\hline January & 0.78 & 0.41 & -2.24 & 0.00 & 0.00 & 0.00 \\
\hline February & 38.00 & 0.44 & 38.45 & 0.00 & 0.00 & 0.00 \\
\hline March & 10.99 & 1.04 & 3.47 & 0.10 & 0.00 & 0.00 \\
\hline April & 1.06 & 0.57 & -6.37 & 0.00 & 0.00 & 0.00 \\
\hline May & 1.06 & 0.91 & 3.48 & 0.51 & 0.00 & 0.00 \\
\hline June & 11.46 & 1.01 & 9.67 & 0.00 & 0.00 & 0.00 \\
\hline
\end{tabular}

\begin{tabular}{|l|r|r|r|r|r|l|} 
July & 16.21 & 1.29 & 17.82 & 1.45 & 0.00 & 0.00 \\
\hline August & 4.19 & 0.10 & -0.39 & 0.00 & 0.00 & 0.00 \\
\hline September & 1.86 & 1.46 & -6.88 & 0.00 & 0.00 & 0.00 \\
\hline October & 3.50 & 0.56 & 0.10 & 0.91 & 0.00 & 0.00 \\
\hline November & 6.04 & 0.45 & -2.39 & 0.00 & 0.00 & 0.00 \\
\hline December & 3.30 & 0.92 & -7.04 & 0.00 & 0.00 & 0.00 \\
\hline
\end{tabular}

Sumber : Pengolahan Data Sekunder

\subsection{Improve}

Penentuan jenis losses dominan dilakukan dengan menggunakan diagram pareto. Diagram pareto dibuat dengan menggunakan persentase kumulatif dari jenis losses yang terjadi.

Dengan melakukan analisis pareto terhadap seluruh jenis losses, akar permasalahan yang sesungguhnya dapat ditemui. Dari diagram pareto memperlihatkan dengan jelas pengaruh six big losses tersebut terhadap efektivitas mesin Coal Crusher-03. Dapat dilihat pada Gambar 6. bahwa Reduced Speed Losses memiliki persentase tertinggi yaitu 58,82\% dengan kerugian waktu sebesar 187,11 jam yang sangat berpengaruh terhadap nilai OEE mesin coal crusher-03 pada tahun 2020. Menurut Limantoro, Reduced Speed Losses merupakan penurunan kecepatan produksi yang timbul ketika kecepatan operasi actual bernilai lebih kecil dibandingkan dengan kecepatan mesin yang telah dirancang untuk operasi (Limantoro, 2013).

Tabel 8. Hasil Perhitungan Six Big Losses mesin Coal Crusher-03 Januari-Desember 2020

\begin{tabular}{|l|c|c|}
\hline \multicolumn{1}{|c|}{ Six Big Losses } & Total (\%) & Rata-Rata (\%) \\
\hline Equipment Failure Losses & 208.80 & 17.40 \\
\hline Setup and Adjustment Losses & 7.84 & 0.65 \\
\hline Reduced Speed Losses & 311.85 & 25.99 \\
\hline Idle and Minor Stoppage Losses & 1.66 & 0.14 \\
\hline Rework Losses & 0.00 & 0.00 \\
\hline Reduce Yield & 0.00 & 0.00 \\
\hline Total & $\mathbf{5 3 0 . 1 5}$ & $\mathbf{4 4 . 1 8}$ \\
\hline
\end{tabular}

Sumber : Pengolahan Data Sekunder 
Tabel 9. Persentase Faktor Six Big Losses mesin Coal Crusher-03

\begin{tabular}{|l|r|r|}
\hline \multicolumn{1}{|c|}{ Six Big Losses } & $\begin{array}{c}\text { Total Time Losses } \\
\text { (Jam) }\end{array}$ & \multicolumn{1}{c|}{$\begin{array}{c}\text { Persentase } \\
\text { (\%) }\end{array}$} \\
\hline Reduced Speed Losses & 187.11 & 58.82 \\
\hline $\begin{array}{l}\text { Equipment Failure } \\
\text { Losses }\end{array}$ & 125.28 & 39.38 \\
\hline $\begin{array}{l}\text { Setup and Adjustment } \\
\text { Losses }\end{array}$ & 4.70 & 1.48 \\
\hline $\begin{array}{l}\text { Idle and Minor } \\
\text { Stoppage Losses }\end{array}$ & 1.00 & 0.31 \\
\hline Rework Losses & 0.00 & 0.00 \\
\hline Reduce Yield & 0.00 & 0.00 \\
\hline Total & $\mathbf{3 1 8 . 0 9}$ & $\mathbf{1 0 0 . 0 0}$ \\
\hline
\end{tabular}

Sumber : Pengolahan Data Sekunder

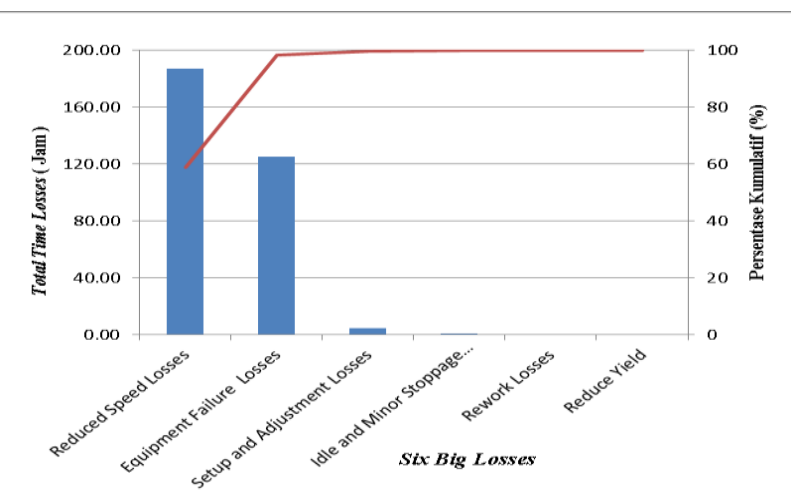

Gambar 6. Diagram Pareto Six Big Losses Mesin Coal Crusher-03 Januari - Desember 2020

Sedangkan untuk mesin Coal Crusher-04, dapat dilihat pada Gambar 7 bahwa Equipment Failure Losses memiliki persentase tertinggi yaitu $62.21 \%$ dengan kerugian waktu sebesar 59,07 jam yang sangat berpengaruh terhadap nilai OEE mesin coal crusher-04 yang mengindikasikan tidak adanya keseimbangan antara waktu operasi dan waktu beban dimana waktu operasi dipengaruhi oleh downtime.

Tabel 10. Hasil Perhitungan Six Big Losses mesin Coal Crusher-04 Januari-Desember 2020

\begin{tabular}{|l|c|c|}
\hline \multicolumn{1}{|c|}{ Six Big Losses } & $\begin{array}{c}\text { Total } \\
(\%)\end{array}$ & $\begin{array}{c}\text { Rata-Rata } \\
(\%)\end{array}$ \\
\hline Equipment Failure Losses & 98.45 & 8.20 \\
\hline Setup and Adjustment Losses & 9.15 & 0.76 \\
\hline Reduced Speed Losses & 47.69 & 3.97 \\
\hline $\begin{array}{l}\text { Idle and Minor Stoppage } \\
\text { Losses }\end{array}$ & 2.97 & 0.25 \\
\hline Rework Losses & 0.00 & 0.00 \\
\hline Reduce Yield & 0.00 & 0.00 \\
\hline Total & $\mathbf{1 5 8 . 2 5}$ & $\mathbf{1 3 . 1 9}$ \\
\hline
\end{tabular}

Sumber : Pengolahan Data Sekunder
Tabel 11. Persentase Faktor Six Big Losses mesin Coal Crusher-04

\begin{tabular}{|l|r|r|}
\hline \multicolumn{1}{|c|}{ Six Big Losses } & $\begin{array}{c}\text { Total Time Losses } \\
(\text { Jam })\end{array}$ & \multicolumn{1}{c|}{$\begin{array}{c}\text { Persentase } \\
\text { (\%) }\end{array}$} \\
\hline $\begin{array}{l}\text { Equipment Failure } \\
\text { Losses }\end{array}$ & 59.07 & 62.21 \\
\hline Reduced Speed Losses & 28.61 & 30.13 \\
\hline $\begin{array}{l}\text { Setup and Adjustment } \\
\text { Losses }\end{array}$ & 5.49 & 5.78 \\
\hline $\begin{array}{l}\text { Idle and Minor } \\
\text { Stoppage Losses }\end{array}$ & 1.78 & 1.88 \\
\hline Rework Losses & 0 & 0.00 \\
\hline Reduce Yield & 0 & 0.00 \\
\hline Total & \multicolumn{2}{|c|}{$\mathbf{9 4 . 9 5}$} \\
\hline \multicolumn{2}{|c|}{ Sumber : Pengolahan Data Sekunder } \\
\hline
\end{tabular}

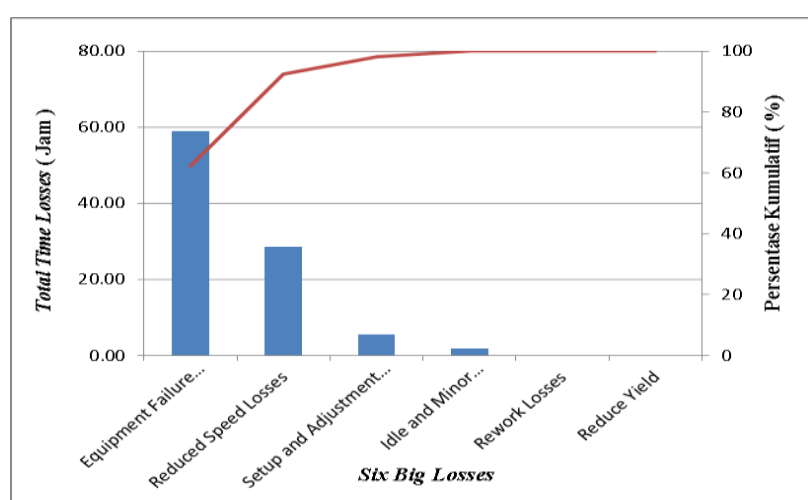

Gambar 7. Diagram Pareto Six Big Losses Mesin Coal Crusher-04 Januari - Desember 2020

Dari 4 jenis losses yang dominan yang telah diidentifikasi, selanjutnya dilakukan identifikasi penyebab masalah losses tersebut dengan menggunakan diagram tulang ikan (fishbone diagram). Dapat dilihat pada gambar 8 identifikasi 4 kategori faktor dari penyebab losses, diantaranya faktor manusia, faktor metode, faktor mesin, dan faktor lingkungan.

\section{Error! Not a valid}

link.

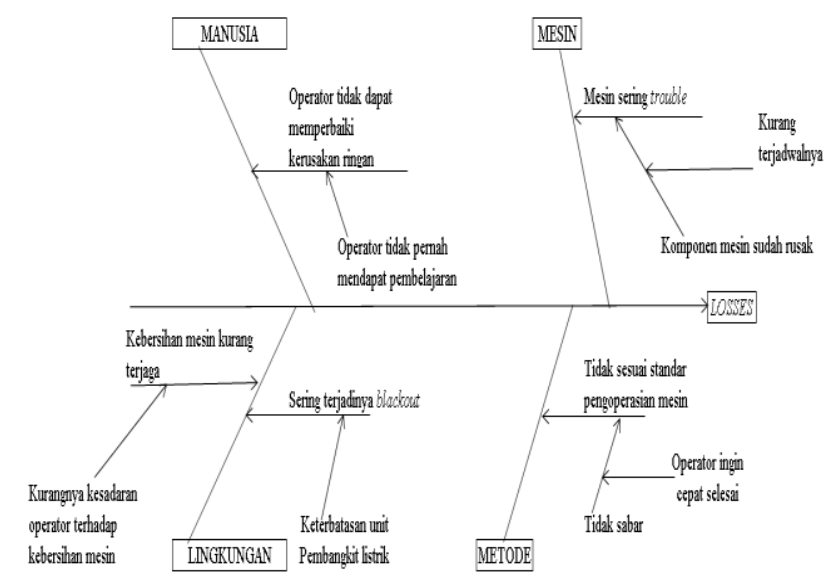

Gambar 8. Diagram Sebab Akibat 
Berdasarkan diagram sebab akibat pada gambar 8, berikut adalah usulan yang diberikan untuk mengurangi losses (down time):

1. Memberikan training sesuai SOP kepada operator.

2. Pemberian pelatihan untuk maintenance kepada operator.

3. Membuat jadwal perawatan secara berkala.

4. Tim FPM harus rutin memeriksa spare part mesin dan harus mempunyai backup yang dianggap penting.

5. Melakukan 5R di area kerja sebelum dan sesudah melakukan pekerjaan.

6. Rutin melakukan pengecekan genset agar mesin siap operasional saat dibutuhkan.

7. Membuat ulang standar operasional mesin.

\subsection{Control}

Berdasarkan analisis yang telah dilakukan di Departemen Fixed Plant Maintenance ( FPM ) PT Berau Coal terhadap mesin coal crusher 03 dan 04 Periode Januari - Desember 2020 didapatkan kesimpulan bahwa Nilai OEE yang diperoleh telah melampaui nilai Standard World OEE yaitu $85 \%$ dimana nilai OEE untuk mesin Coal Crusher-03 periode Januari Desember 2020 adalah $88 \%$ sedangkan untuk mesin Coal Crusher-04 nilai OEE pada periode Januari Desember 2020 adalah $86 \%$. Selanjutnya pada analisis Six Big Losses terhadap mesin Coal Crusher-03 kerugian paling dominan adalah faktor Reduced Speed Losses dengan total time losses 187,11 jam atau persentase $58,82 \%$ dari keenam faktor six big losses. Untuk mesin coal crusher-04 kerugian paling dominan adalah faktor Equipment Failure Losses dengan total time losses 59,07 jam atau persentase $62,21 \%$ dari keenam faktor six big losses.

Tahapan akhir dari pendekatan DMAIC adalah control. Tahapan ini dilakukan atau diimplementasikan pada Departemen Fixed Plant Maintenance berupa Small Group Activity, sehingga efektivitas dan produksi Coal Crusher terus meningkat. Dalam tahap ini perlu adanya suatu rekaman atau histori data perbaikan sehingga dapat dilakukan suatu perbandingan apakah proses dapat lebih baik dibandingkan dengan proses perbaikan sebelumnya. Beberapa alat yang dapat digunakan untuk melakukan hal ini diantaranya adalah, check sheet, kinerja baseline, quality report, dan pendokumentasian. Dengan rutin dan konsisten penerapan Small Group Activity pada Departemen Fixed Plant Maintenance (FPM) efektivitas dan produktivitas dari mesin Coal Crusher 03 dan 04 dapat terus ditingkatkan melalui metode Six Sigma.

\section{KESIMPULAN}

Divisi Fixed Plant Maintenance pada PT Berau Coal telah melakukan pengendalian kualitas menggunakan metode six sigma dengan melakukan analisis DMAIC (Define, Measure, Analyse, Improve, Control) pada setiap tahapan produksi. Hasil yang diperoleh Nilai OEE telah melampaui nilai Standard World OEE 85\% yaitu
87\%. Untuk Losses yang dominan disebabkan karena tingginya nilai Reduced Speed Losses dengan persentase 58,82\% dan Equipment Failure Losses dengan persentase $62,21 \%$. Usulan perbaikan kepada divisi Fixed Plant Maintenance memberikan training dan pelatihan kemudian pengetahuan dengan SOP sebagai dasar untuk mengoperasikan mesin dengan benar sehingga operator mengerti apabila ada yang tidak normal pada mesin tersebut, perusahaan harus memberikan arahan atau penjadwalan yang lebih ketat untuk kebersihan area kerja atau mesin sebelum atau sesudah bekerja, agar tercipta kondisi nyaman dan aman saat bekerja. Memberikan standar perawatan yang baik sesuai dengan manual book yang terlebih dahulu di tentukan oleh bagian maintenance atau teknisi, melakukan program total preventive maintenance dengan menjadwalkan perawatan secara rutin, sigap dan cepat apabila mesin terjadi breakdown, mempunyai backup pada komponen-komponen mesin yang di anggap sangat penting dan vital.

\section{SARAN}

Departemen Fixed Plant Maintenance rutin mengadakan kegiatan peningkatan SDM berupa training pada pengendalian kualitas, dan training basic maintenance pada operator.

Selanjutnya untuk penelitian berikutnya dapat menggunakan metode-metode OEE ataupun maintenance yang lain dalam melakukan evaluasi kinerja mesin-mesin yang mengalami penurunan kinerja dan produktivitas di Departemen Fixed Plant Maintenance.

\section{DAFTAR PUSTAKA}

Brodny, J., Tutak, M., 2017. Application of elements of TPM strategy for operation analysis of mining machine, in: IOP Conference Series: Earth and Environmental Science. IOP Publishing, p. 42019.

Dogra, M., Sharma, V.S., Sachdeva, A., Dureja, J.S., 2011. TPM-a key strategy for productivity improvement in process industry. J. Eng. Sci. Technol. 6, 1-16.

Evans, J.R., Lindsay, W.M., 2014. An introduction to Six Sigma and process improvement. Cengage Learning.

Gaspersz, V., 2011. Sistem manajemen kinerja terintegrasi balanced scorecard dengan malcolm baldrige dan lean six sigma supply chain management. Jakarta PT Gramedia Pustaka Utama.

Gupta, P., Vardhan, S., 2016. Optimizing OEE, productivity and production cost for improving sales volume in an automobile industry through TPM: a case study. Int. J. Prod. Res. 54, 2976 2988.

Hooi, L.W., Leong, T.Y., 2017. Total productive maintenance and manufacturing performance improvement. J. Qual. Maint. Eng.

Limantoro, D., 2013. Total Productive Maintenance di PT. X. J. Titra 1, 13-20. 
Modgil, S., Sharma, S., 2016. Total productive maintenance, total quality management and operational performance: An empirical study of Indian pharmaceutical industry. J. Qual. Maint. Eng.

Pourjavad, E., Shirouyehzad, H., Shahin, A., 2013. Selecting maintenance strategy in mining industry by analytic network process and TOPSIS. Int. J. Ind. Syst. Eng. 15, 171-192.

Prasetyoaji, D.K., Abadi, C.S., Syujak, M., 2019. Analisis Efektivitas Coal Crusher Dengan Metode Overall Equipment Effectivenes, in: Seminar Nasional Teknik Mesin 2021. pp. 1116-1121.

Rastegari, A., Salonen, A., 2015. Strategic maintenance management: Formulating maintenance strategy. Int. J. COMADEM 18, 5-14.

Rimawan, E., Raif, A., 2016. Analisis Pengukuran Nilai Overall Equipment Effectiveness (Oee) pada Proses Packaging di Line 2 (Studi Kasus PT. Multi Bintang Indonesia. Tbk). Sinergi 20, 140-148.

Saleem, F., Nisar, S., Khan, M.A., Khan, S.Z., Sheikh, M.A., 2017. Overall equipment effectiveness of tyre curing press: a case study. J. Qual. Maint. Eng.

Salonen, A., 2011. Strategic maintenance development in manufacturing industry.

Shirose, K., 2017. TPM for workshop leaders. Routledge.

Sin, A.B., Zailani, S., Iranmanesh, M., Ramayah, T., 2015. Structural equation modelling on knowledge creation in Six Sigma DMAIC project and its impact on organizational performance. Int. J. Prod. Econ. 168, 105-117.

Singh, K., Ahuja, I.S., 2014. Effectiveness of TPM implementation with and without integration with TQM in Indian manufacturing industries. J. Qual. Maint. Eng.

Sugiyono, D., 2013. Metode penelitian pendidikan pendekatan kuantitatif, kualitatif dan R\&D.

Suzuki, T., 2017. TPM in process industries. Routledge.

Wicakmoko, J., 2016. Pengembangan Kapasitas Pembangkit Listrik Tenaga Uap Berdasarkan Potensi Batubara di Kalimantan Tengah. Univ. Muhammadiyah Yogyakarta.

\section{UCAPAN TERIMA KASIH}

Penulis mengucapkan terima kasih kepada Kemendikbud-Ristek yang telah memberikan dukungan melalui pendanaan Dosen Pemula Tahun 2020, Departemen Fised Plant Maintenance (FPM), Manajemen PT. Berau Coal serta Civitas Poltek Simas Berau Coal atas dukungannya selama penelitian berlangsung. 